\title{
Quality characteristics of cookies added with Takju pomace powder
}

\author{
Chae-Yun Im, Mi-Hyang Kim, Woo-Won Kang * \\ Department of Food and Food Service industry, Kyungpook National University, Sangju 37224, Korea
}

탁주 주박 분말을 첨가한 쿠키의 품질 특성

\author{
임채윤 - 김미향 - 강우원 * \\ 경북대학교 식품외식산업학과
}

\begin{abstract}
This study investigated the quality characteristics of cookies added with the powder of pomace powder, which was produced as a by-product in Korean rice wine (Takju). The quality of cookies was evaluated based on moisture content, color, hardness, and sensory evaluation. Cookies were prepared by addition of $0,5,10$, and $15 \%$ Takju pomace powders to basic flour formulation. The $\mathrm{pH}$ values of dough added with Takju pomace powder were 3.04-6.52, which was lower than that of the control group. The moisture contents of cookies were $6.92-6.52 \%$ and were lowest in cookies added with $15 \%$ Takju pomace powder. The $\mathrm{L}$ value was reduced according to the increase in Takju pomace powder. On the contrary, a value increased. Especially, a value of the control was negative (-0.96) while those of cookies added with Takju pomace powder were positive. There were no significant differences in the b value of these cookies. For texture, hardness of cookies was lowest in $15 \%$ Takju pomace powder cookies. The results of the sensory evaluation compared to cookies with $10 \%$ powder Takju pomace were superior in appearance, taste and overall preference.
\end{abstract}

Key words : cookies, Takju pomace, quality characteristics, sensory evaluation

\section{서 론}

국민소득이 증가하고 여성의 사회진출이 증가, 외식산업 의 발달, 단체급식의 발달, 서구형 식생활 유입 등에 따라 과거 밥 위주의 식사였던 국민의 식생활이 빵과 국수 등 밀가루 음식으로 바뀌고 있으며 더불어 식품 문화의 단순 화, 간편화, 외식화가 이루어지고 있다. 특히 쿠키, 빵 등 바쁜 현대인들이 간편하게 간식이나 식사대용으로 섭취할 수 있는 제과·제빵류의 소비가 증가하는 추세이며 국가통 계포털(KOSIS)에 의하면 우리나라의 과자-비스킷류 생산 량은 2009년에 123,209톤에서 2014년에는 413,111톤으로 3 배 이상의 성장을 보이며 점차적으로 소비가 증가하고

*Corresponding author. E-mail : wwkang@knu.ac.kr Phone : 82-54-530-1303, Fax : 82-54-530-1309

Received 21 July 2016; Revised 21 November 2016; Accepted 16 December 2016.

Copyright (c) The Korean Society of Food Preservation. All rights reserved.
있다(1). 제과류 중 쿠키는 한식과자에 대응하는 서양의 대표적인 기호식품으로써 수분함량이 $5 \%$ 이하로 낮고 크 기가 작은 과자를 일컫는데, 이러한 특징 때문에 미생물적 인 변패가 적고 저장성이 우수하여 언제 어디서나 먹기 간편하고 맛이 좋아 현대인들이 주된 간식으로 이용되고 있다(2). 한편, 최근의 트랜드인 웰빙에 맞추어 현재 소비자 들은 단순히 에너지를 얻기 위해 음식을 섭취하는 것이 아니라 친환경적이며 건강과 기능적인 면을 생각하는 식생 활 패턴으로 전환되고 있으며 앞으로도 계속해서 친환경 적, 기능적 식품에 대한 기대치가 높아 질것으로 예상된다.

주박(酒粕)이란 탁주 제조 시 생성되는 부산물로서, 현재 탁주공장에서는 사용한 원료 곡물의 약 $20 \%$ 가 주박의 형태 로 배출되고 있는 일종의 식품 산업 폐기물이다(3). 막걸리 를 제조했을 때 남는 주박(술지게미)을 이용한 동물실험 결과 고혈압 억제 및 혈당개선 효과가 있으며(4), 주박 식이 섬유는 비만 환자에서 허리둘레, 중성 지방 및 식후 혈당과 인슐린과 같은 비만, 당뇨 및 지질 대사 이상과 관련된 인자 들을 개선시키는 효과가 있다는 보고가 있다(5). 일본에서 
도 청주를 거르고 난 후의 술지게미인 주박의 생리기능에 대한 활발한 연구를 하고 있으며, 주박이 당뇨, 고혈압, 골다 공증 등에 효과가 있으며, 뇌경색, 심근경색 및 동맥경화를 예방하며, 알레르기체질을 개선하고, 미백효과를 나타내는 등 다양한 건강기능성을 갖고 있음을 보고하고, 이들 성분 을 이용한 건강식품 또는 기능성 제품의 개발에 박차를 가하고 있다(6). 현재 우리나라에서는 주박과 관련된 연구 결과로는 제빵 첨가제(7), 주박을 첨가한 브라운소스(8), 국수(9), 약과(10), 고추장(11) 등으로 아직 연구가 미미하 다. 본 연구에서는 식품 산업 부산물인 주박을 식품재료로 써 재활용하여 쿠키를 제조하고 $\mathrm{pH}$, 수분함량, 색도와 조직 감, 관능평가를 통하여 주박 분말을 첨가한 쿠키의 품질특 성을 조사하였다.

\section{재료 및 방법}

\section{실험재료}

주박분말 첨가 쿠키의 제조를 위해 사용된 주박은 은척 양조장(Sangju, Korea)에서 쌀막걸리 제조 후 생산 된 것을 사용하였으며 $40^{\circ} \mathrm{C}$ 에서 4 시간 동안 열 풍건조하고 food mixer로 분쇄 후 $20 \mathrm{mesh}$ 를 통과시킨 분말을 사용하였으며 밀가루, 설탕은 (주)삼양사(Sungnam, Korea)의 큐원 제품 을, 쇼트닝은 서울우유, 베이킹파우더(baking powder)는 (주)신광식품산업사(Gimhae, Korea) 제품, 계란은 상주 농 산(Sangju, Korea)제품을 사용하였다.

\section{쿠키 제조}

주박분말을 첨가한 쿠키 제조 방법은 Table 1에 나타낸 바와 같다. 계량된 쇼트닝을 반죽기(K5SS Kitchen Aid Co., Joseph, MI, USA)에 넣고 2단으로 1 분간 부드럽게 풀어준 다음, 설탕을 2-3회 나누어 넣고 4단에서 2분간 작동하였으 며 계란을 투입하여 1 분간 작동시켜 크림화 하였다. 완성된 크림형 반죽은 2 회에 걸쳐 체에 친 베이킹파우더, 주박, 밀가루를 가볍게 혼합하여 실온에서 30 분간 휴지시켰다.

Table 1. Ingredient formula of cookie added with Takju pomace powder

\begin{tabular}{ccccc}
\hline \multirow{2}{*}{ Ingredient $(\mathrm{g})$} & \multicolumn{4}{c}{ Addition rate of Takju pomace powder (\%) } \\
\cline { 2 - 5 } & 0 & 5 & 10 & 15 \\
\hline Wheat flour & 100 & 95 & 90 & 85 \\
Sugar & 40 & 40 & 40 & 40 \\
Shortning & 40 & 40 & 40 & 40 \\
Whole egg & 20 & 20 & 20 & 20 \\
Baking powder & 2 & 2 & 2 & 2 \\
Takju pomace powder & 0 & 5 & 10 & 15 \\
Water & 10 & 10 & 10 & 10 \\
\hline
\end{tabular}

휴지시킨 반죽은 높이 $3 \mathrm{~mm}$ 로 밀고 원형 쿠키틀로 찍어 평철판에 사방 $2 \mathrm{~cm}$ 간격으로 배치한 후, 오븐(Woo jung machinery Co., Seoul, Korea)에 넣고 윗불 $180^{\circ} \mathrm{C}$, 아랫불 $140^{\circ} \mathrm{C}$ 에서 13 분간 구웠다. 구운 쿠키는 1 시간 동안 실온에 서 냉각시킨 후, poly propylene film으로 밀봉해 두었다가 24시간 후에 시료로 사용하였다.

\section{반죽의 $\mathrm{pH}$ 측정}

주박분말의 첨가량을 달리한 쿠키반죽의 $\mathrm{pH}$ 측정은 $\mathrm{AOAC}$ 법(12)을 변형하여 쿠키반죽 $5 \mathrm{~g}$ 을 증류수 $50 \mathrm{~mL}$ 에 섞어서 5 분간 혼합하여 현탁액의 상태로 만들어 $\mathrm{pH}$ meter (Model D-51 Horiba, Japan)를 이용하여 3회 반복 측정하고 그 평균값을 구하였다.

\section{수분함량 측정}

주박분말의 첨가량을 달리하여 제조한 쿠키의 수분함량 은 시료 $5 \mathrm{~g}$ 을 적외선 수분 측정기(FD-240-2 Kett, Tokyo, $\mathrm{Japan}$ )를 이용하여 $105^{\circ} \mathrm{C}$ 에서 3 회 반복 측정하여 평균값을 구하였다(13).

\section{쿠키의 색도 측정}

주박분말의 첨가량을 달리하여 제조한 쿠키의 색도는 굽기가 끝난 쿠키를 실온에서 1 시간 냉각 시킨 후, 색차계 (Minolta CR-400/410, Tokyo, Japan)를 사용하여 명도( lightness, L), 적색도(redness, a), 황색도(yellowness, b)을 3 회 반복 측정하여 그 평균값으로 나타내었다.

\section{쿠키의 조직감 측정}

주박분말의 첨가량을 달리하여 제조한 쿠키의 조직감은 texture analyser(TA-XT2, stable micro system Ltd., Haslemere, England)를 이용하여 경도(hardness)를 측정하 였으며 Table 2 와 같은 조건으로 3 회 반복 측정한 후, 그 평균값을 구하였다.

Table 2. The operating condition of texture profile analyzer

\begin{tabular}{cc}
\hline Measurement & Condition \\
\hline Probe type & $5 \mathrm{~mm}$ cylinder \\
Pre-test speed & $2.0 \mathrm{~mm} / \mathrm{sec}$ \\
Test speed & $0.5 \mathrm{~mm} / \mathrm{sec}$ \\
Post-test speed & $10.0 \mathrm{~mm} / \mathrm{sec}$ \\
Distance & $4 \mathrm{~mm}$ \\
Force & $20 \mathrm{~g}$ \\
Time & $5 \mathrm{sec}$ \\
\hline
\end{tabular}

\section{관능평가}

주박분말의 첨가량을 달리하여 제조한 쿠키의 관능평가 는 본 실험의 목적과 쿠키의 특성 및 평가 방법에 대해 
충분히 숙지시킨 남·여 대학생 60 명을 대상으로 실시하였 으며 색(color), 향(flavor), 조직감(texture), 맛(taste), 전반적 인 선호도(overall acceptability)를 5점 기호 척도법(1점, 매 우 나쁘다; 5점, 매우 좋다)을 사용하여 평가하였다.

\section{통계 처리}

3회 반복 측정한 각 실험 결과와 관능평가 결과는 SPSS WIN 12.0 program을 이용하여 평균과 표준편차를 구하고 일원배치분산분석(one way ANOVA)을 실시하였으며, 각 시료간의 유의성은 Duncan's multiple rang test를 이용하여 검증하였다 $(\mathrm{p}<0.05)$.

\section{결과 및 고찰}

\section{반죽의 수분함량 및 $\mathrm{pH}$}

주박 분말의 수분 햠량은 $16.2 \pm 1.02 \%$ 이었으며 주박 분 말을 첨가한 쿠키 반죽의 $\mathrm{pH}$ 는 Table 3 과 같았다. 주박 분말의 $\mathrm{pH}$ 는 $3.29 \pm 0.34$ 이었으며 쿠키 반죽의 $\mathrm{pH}$ 는 무첨가 구가 $3.99 \pm 0.09$ 이었으며 $5 \%$ 첨가구는 $3.04 \pm 0.21,10 \%$ 첨가 구는 $4.12 \pm 0.34$, 주박 $15 \%$ 첨가구는 $5.78 \pm 0.51$ 로 주박 분말 $5 \%$ 첨가구에서는 무첨가보다 낮아지고 $10 \%$ 와 $15 \%$ 에서는 무첨가보다 높았으며 $15 \%$ 첨가구에서 가장 높았다. 이는 주박의 $\mathrm{pH}$ 가 $3.01 \pm 0.25$ 이었으며 이를 감안해보면 열풍 건 조 과정에서 주박에 존재하는 휘발성 유기산의 휘발에 의하 여 분말의 $\mathrm{pH}$ 를 다소 증가시키는 결과를 나타내었으나 잔 존하는 비휘발성 유기산에 의하여 $5 \%$ 첨가 수준의 첨가구 에서는 반죽의 $\mathrm{pH}$ 를 감소시키나 $10 \%$ 이상의 첨가구에서는 주박 영양소에 의한 중화작용으로 반죽의 $\mathrm{pH}$ 를 오히려 증 가시키는 것으로 사료된다.

Table 3. $\mathrm{pH}$ of dough and moisture contents of cookie added with Takju pomace powder

\begin{tabular}{ccccc}
\hline \multirow{2}{*}{ Parameter } & \multicolumn{4}{c}{ Addition rate of Takju pomace powder (\%) } \\
\cline { 2 - 5 } & 0 & 5 & 10 & 15 \\
\hline $\mathrm{pH}$ & $3.99 \pm 0.09^{\mathrm{cl})}$ & $3.04 \pm 0.21^{\mathrm{d}}$ & $4.12 \pm 0.34^{\mathrm{b}}$ & $5.78 \pm 0.51^{\mathrm{a}}$ \\
\hline Moisture contents & $6.92 \pm 0.01^{\mathrm{c}}$ & $6.93 \pm 0.01^{\mathrm{c}}$ & $6.79 \pm 0.10^{\mathrm{b}}$ & $6.52 \pm 0.05^{\mathrm{a}}$
\end{tabular}

${ }^{1)}$ Means in each row with different superscript letter are significantly different by Duncan's multiple range test $(\mathrm{p}<0.05)$.

\section{쿠키의 수분함량}

주박분말의 첨가량을 달리하여 제조한 쿠키의 수분함량 측정 결과는 Table 3 에 나타낸 바와 같다. 주박 무첨가 대조 구 $6.92 \%$ 에 비하여 주박 $5 \%$ 첨가구에서는 $6.93 \%, 10 \%$ 첨 가구에서 $6.79 \%, 15 \%$ 첨가구에서 $6.52 \%$ 로 $5 \%$ 첨가 수준에 서는 무첨가와 유의적인 차이를 보이지는 않으나 $10 \%$ 와 $15 \%$ 첨가 수준으로 수분함량이 다소 낮아지는 것으로 나타
났다. 주박 분말의 수분 함량이 $16.2 \pm 0.73 \%$ 이고 사용한 밀가루의 수분함량 $15.8 \pm 1.02 \%$ 를 고려해보면 주박 첨가가 쿠키 반죽의 전체 수분 함량에는 유의적인 차이를 나타내지 는 않으나 반죽을 오븐에서 굽는 과정에서 발생하는 수분증 발이 주박 첨가 반죽에서 더 활발하게 일어난 때문으로 사료된다. Jang 등(15)이 미강의 수분함량이 밀가루보다 낮고, 미강 분말 첨가량이 증가할수록 쿠키의 수분이 낮아 졌음을 보고한 연구결과와 유사하였다.

\section{색 도}

주박분말의 첨가량을 달리하여 제조한 쿠키의 색도를 측정할 결과는 Table 4 에 나타낸 바와 같다. 쿠키의 색은 일정한 조건하에서 주로 당에 의한 영향이 크고, 환원당에 의한 비효소적 maillard 반응 및 열에 불안정한 당에 의한 캐러멜화 반응에 의해 가장 큰 영향을 받으며(16) 첨가된 부재료에 의해 차이를 보인다(17). L 값은 대조구가 79.59 로 높게 측정되었으며 $15 \%$ 첨가구가 69.66 으로 낮게 나타 나서 주박 첨가량이 증가할수록 감소하는 경향을 보였다. $\mathrm{a}$ 값은대조구가 -0.96으로 녹색도 영역의 값을 보인 반면, 주박 분말 첨가 $15 \%$ 첨가구가 3.51 로 높게 나타났으며 유의 적으로 증가하는 성향을 보였다. 이는 주박분말이 maillard 반응과 열에 의한 캐러멜화 반응이 잘 되기 때문이라 판단 되며, 주박분말 제조 과정 중 갈변현상이 일어났거나, 쿠키 제조과정에서 갈변화가 일어난 것으로 보인다. 이러한 결 과와 관련하여 마늘 페이스트 첨가량이 높을수록 유의적으 로 감소하는 경향을 보인다는 연구결과와 유사하며(14) 첨 가물인 주박이 명도가 낮아 그 자체의 색에 따라 첨가물의 양이 증가할수록 쿠키의 명도를 감소시키는 것으로 판단된 다. b값은 4종의 시료가 29.26-28.08의 범위를 나타내어 주 박 분말 첨가유무에 따른 유의적인 차이를 나타내지 않았 다. 이는 마늘페이스트 첨가쿠키의 $\mathrm{b}$ 값이 마늘 페이스트 첨가량에 비례하여 감소함을 보고한 연구결과(14)와 현미 가루 첨가 쿠키의 황색도가 흑미가루의 첨가량의 증가에 따른 유의적으로 증가하였음을 보고한 연구결과(19)와 차 이를 보인 것이었다.

Table 4. Hunter's color value of cookie added with Addition rate of Takju pomace powder

\begin{tabular}{cccc}
\hline \multirow{2}{*}{$\begin{array}{c}\text { Addition rate } \\
\text { of Takju pomace powder }(\%)\end{array}$} & \multicolumn{3}{c}{ Color } \\
\cline { 2 - 4 } & $\mathrm{L}$ & $\mathrm{a}$ & $\mathrm{b}$ \\
\hline 0 & $79.59 \pm 0.29^{\mathrm{a} 1)}$ & $-0.96 \pm 0.16^{\mathrm{a}}$ & $29.26 \pm 0.16^{\mathrm{a}}$ \\
5 & $75.47 \pm 0.78^{\mathrm{b}}$ & $0.13 \pm 0.79^{\mathrm{b}}$ & $27.54 \pm 0.58^{\mathrm{a}}$ \\
10 & $73.76 \pm 0.77^{\mathrm{b}}$ & $1.61 \pm 0.55^{\mathrm{c}}$ & $28.48 \pm 0.82^{\mathrm{a}}$ \\
15 & $69.66 \pm 0.96^{\mathrm{c}}$ & $3.51 \pm 0.46^{\mathrm{d}}$ & $28.08 \pm 0.25^{\mathrm{a}}$ \\
\hline
\end{tabular}

${ }^{1}$ Means in each row with different superscript letter are significantly different by Duncan's multiple range test $(p<0.05)$. 


\section{경 도}

주박분말의 첨가량을 달리하여 제조한 쿠키를 실온에서 1시간 냉각시킨 다음, 경도(hardness)의 특성을 측정한 결과 는 Table 5에 나타낸 바와 같았다. 주박 무첨가 대조구는 $755.01 \pm 89.34$ 이었으며 $5 \%$ 첨가구 $744.21 \pm 130.88$ 로 무첨 가와 유의적인 차이를 보이지는 않으나 $10 \%$ 첨가는 $695.47 \pm 45.13,15 \%$ 첨가가 $539.70 \pm 90.63$ 으로 $10 \%$ 이상의 첨가 수준에서는 주박 첨가량이 증가할수록 경도는 감소하 는 것으로 나타났다. 일반적으로 쿠키의 경도는 첨가되는 재료와 그 수분함량에 따라 달라지는 경향이 있고(19), 본 연구에서 주박 첨가 쿠키의 경우 수분함량이 많을수록 경도 가 증가하는 경향을 보인 다는 Lee 등 (21)의 결과와는 상이 한 결과를 보였다. 이는 주박분말의 원재료인 쌀에 함유되 어 있는 아밀로스의 반죽형성에 필요한 수분과 결합함으로 써 글루텐 형성을 억제하고 제품을 부드럽게 하는 연화작용 (22)에 따른 것으로 판단된다. 이는 흑미분말(19)이나 수분 함량이 밀가루보다 높은 마늘즙(23)을 첨가한 쿠키의 연구 결과와 유사하였다.

Table 5. Texture properties of cookie added with Takju pomace powder

\begin{tabular}{lcccc}
\hline \multirow{2}{*}{ Parameter } & \multicolumn{4}{c}{ Addition rate of Takju pomace powder (\%) } \\
\cline { 2 - 5 } & 0 & 5 & 10 & 15 \\
\hline Hardness & $755.01 \pm 89.34^{\text {al) }}$ & $744.21 \pm 130.88^{\mathrm{a}}$ & $695.47 \pm 45.13^{\mathrm{b}}$ & $539.70 \pm 90.63^{\mathrm{c}}$ \\
\hline${ }^{1}$ Means in each row with different superscript letter are significantly different by \\
Duncan's multiple range test $(\mathrm{p}<0.05)$.
\end{tabular}

\section{관능평가}

주박분말의 첨가량을 달리하여 제조한 쿠키의 관능 선호 도 평가결과는 Table 6에 나타낸 바와 같다. 외관은 무첨가 구가 $3,20 \pm 0,94$ 인 것에 비하여 주박 분말 $5 \%$ 와 $10 \%$ 첨가구 에서 $3.44 \pm 0.90$ 와 $3.75 \pm 0.82$ 로 $10 \%$ 에서 가장 높았으며 $15 \%$ 첨가에서는 $3.32 \pm 1.12$ 으로 오히려 낮아져 무첨가와 비슷한 수준인 것으로 평가하였다. 향에서는 무첨가가 $2.73 \pm 0.85$ 인 것과 비교하여 주박의 첨가량이 증가함에 비 례하여 함께 증가 하여서 $15 \%$ 첨가구에서 $3.12 \pm 0.91$ 로 가 장 높게 평가하여서 주박 첨가로 향의 기호도가 높아지는 것으로 나타났다. 맛과 질감 기호도는 $10 \%$ 첨가구에서 가 장 높게 평가하였으며 주박 첨가가 기호도를 높이는 것으로 나타났다 $(\mathrm{p}<0.05)$. 종합적인 기호도 평가에서는 무첨가보 다 주박 첨가가 좋은 것으로 평가하였고 주박 분말 $10 \%$ 첨가가 가장 높은 것으로 나타났다. 이상의 결과를 살펴보 면, 주박 분말의 첨가가 외관, 맛, 질감 등의 기호도를 향상 시키는 것으로 나타났으며 특히 주박 특유의 향도 막걸리향 이 친숙하고 거부감을 일으키지 않는 것으로 평가하였다. 이상의 결과를 토대로 주박 첨가 쿠키의 첨가 수준은 $10 \%$ 가 가장 좋은 것으로 나타났다. 이는 폐기물로 버려지는
주박의 이용도를 높이고 고부가 가치적 이용전환과 새로운 제품으로서 개발할 수 있는 가능성을 제시 할 수 있을 것으 로 사료된다.

Table 6. Sensory properties of cookie added with Takju pomace powder

\begin{tabular}{ccccc}
\hline \multirow{2}{*}{$\begin{array}{c}\text { Sensory } \\
\text { evaluation }\end{array}$} & \multicolumn{4}{c}{ Addition rate of Takju pomace powder (\%) } \\
\cline { 2 - 5 } & 0 & 5 & 10 & 15 \\
\hline Appearance & $3.20 \pm 0.94^{\mathrm{bl})}$ & $3.44 \pm 0.90^{\mathrm{ab}}$ & $3.75 \pm 0.82^{\mathrm{a}}$ & $3.32 \pm 1.12^{\mathrm{b}}$ \\
Flavor & $2.73 \pm 0.85^{\mathrm{c}}$ & $2.98 \pm 0.90^{\mathrm{b}}$ & $3.08 \pm 0.93^{\mathrm{a}}$ & $3.12 \pm 0.91^{\mathrm{a}}$ \\
Taste & $2.81 \pm 1.03^{\mathrm{c}}$ & $3.32 \pm 0.91^{\mathrm{a}}$ & $3.54 \pm 1.01^{\mathrm{a}}$ & $3.12 \pm 1.19^{\mathrm{b}}$ \\
Texture & $2.88 \pm 0.89^{\mathrm{c}}$ & $3.17 \pm 1.04^{\mathrm{ab}}$ & $3.37 \pm 0.85^{\mathrm{a}}$ & $3.20 \pm 1.01^{\mathrm{a}}$ \\
Overall & $2.98 \pm 0.90^{\mathrm{c}}$ & $3.25 \pm 0.92^{\mathrm{a}}$ & $3.47 \pm 0.77^{\mathrm{a}}$ & $3.26 \pm 1.02^{\mathrm{a}}$ \\
\hline
\end{tabular}

${ }^{11}$ Means in each row with different superscript letter are significantly different by Duncan's multiple range test $(\mathrm{p}<0.05)$.

\section{요 약}

본 연구에서는 탁주 부산물로 얻어지는 주박을 첨가한 쿠키를 제조하고 5-15\% 수준으로 첨가하고 이에 따른 쿠키 의 $\mathrm{pH}$, 수분함량, 색도와 조직감, 관능평가를 통하여 품질 특성을 조사하였다. 주박 분말의 첨가량을 달리하여 제조 한 쿠키 반죽의 $\mathrm{pH}$ 는 3.04-6.52 수준으로 주박 분말 $5 \%$ 첨가구에서는 무첨가보다 낮아지고 $10 \%$ 이상에서는 주박 첨가량이 증가할수록 $\mathrm{pH}$ 는 높아지는 것으로 나타났다. 쿠 키의 수분함량은 주박 $5 \%$ 첨가 수준은 무첨가와 유의적 차이를 보이지 않으나 $10 \%$ 이상의 첨가에서는 점차 낮아 지는 경향을 보였다. 색도는 주박의 첨가량이 증가하면서 $\mathrm{L}$ 값과 $\mathrm{b}$ 값은 유의적으로 감소하는 경향을 나타내었으며 $\mathrm{a}$ 값은 증가하는 경향을 보였다. 관능평가를 실시한 결과, 주박 분말 $10 \%$ 첨가구에서 외관과 맛에 대한 기호도가 가장 높은 것으로 평가하였고, 향과 질감 기호도에서는 $5 \%$ 가 가장 높았다 $(\mathrm{p}<0.05)$ 종합적인 기호도가 가장 높은 것으 로 평가한 주박 첨가량은 $10 \%$ 인 것으로 평가하였다.

\section{감사의 글}

본 연구는 2015학년도 경북대학교 복현학술연구비의 지 원에 의해 수행되었음.

\section{References}

1. Quantities of production, shipment (Domestic, Export) (2015) Available from: http://kosis.kr. Accessesd Oct. 20

2. Cho HS, Park BH, Kim KH, Kim HA (2006) 
Antioxidative effect and quality characteristics of cookies made with sea tangle powder. Korean J Food Culture, 21, 541-549

3. Kim SM, Cho WK (2006) Effects of Takju (Korean turbid rice wine) lees on the serum glucose levels in streptozotocin induced diabetic rats. Korean J Food Culture, 21, 638-643

4. Chandalia M, Garg A, Lutjohann D, von Bergmann K, Grundy SM, Brinkley LJ (2000) Beneficial effects of high dietary fiber intake in patients with type 2 diabetes mellitus. N Engl J Med, 342, 1392-1398

5. Lee MS (2010) Dietary fiber from lees of unpolished rice: clinical effect on the obese. MS Thesis, Ajou University, Korea, p 7

6. Hattori I, Sato K, Suzuki T, Kamiya M, Kato N (2010) The effect of the material and processing time on the nutritive value of the Shochu condensed distiller soluble. National Agricultural Research Center for Kyushu Okinawa Region, 53, 175-181

7. Jeong JW, Park KJ (2006) Quality characteristics of loaf bread added with Takju powder. Korean J Food Sci Technol, 38, 52-58

8. Lee JP (2008) The sensory characteristics of brown sauce by adding different ratios of Jubak. The Korean J Culinary Research, 14, 152-160

9. Kim SM, Yoon CH, Cho WK (2007) Quality characteristics of noodle added with Takju (Korean turbid rice wine) lees. Korean J Food Culture, 22, 359-364

10. Cho EJ, Yang MO, Kang HJ (2007) Physicochemical characteristics of Yackwa with added rice wine cake. J East Asian Soc Dietary Life, 17, 94-102

11. Lee KS, Kim DH (1991) Effect of sake cake on the quality of low salted Kochuzang. Korean J Food Sci Technol, 23, 109-115

12. AOAC (1996) Approved methods of analysis. 15th ed, Association of Official Analytical Chemists, Washington DC, USA, p 943
13. Chae SK (2009) Food analysis. Jigumonhwasa Co, Seoul, Korea, p 22

14. Kim AJ, Joung KH, Shin SM, Lim HJ, Cho JC (2010) Quality characteristics of cookies with garlic paste. Journal of the Korea Academia-Industrial cooperation Society, 11, 2178-2184

15. Jang KH, Kwak EJ, Kang WW (2010) Effect of rice bran powder on the quality characteristics of cookie. Korean J Food Preserv, 17, 631-636

16. Kim HY, Jeong SJ, Heo MY, Kim KS (2002) Quality characteristics of cookies prepared with varied levels of shredded garlics. Korean J Food Sci Technol, 34, 637-641

17. Lee JS, Jeong SS (2009) Quality characteristics of cookies prepared with button mushroom (Agaricus bisporous) powder. Korean J Food Cookery Sci, 25, 98-105

18. Jung S, Kang WW (2011) Quality characteristics of cookies prepared with flour partly substituted by used coffee grounds. Korean J Food Preserv, 18, 33-38

19. Lee JS, Oh MS (2006) Quality characteristics of cookies with black rice flour. Korean J Food Cookery Sci, 22, 193-203

20. Kim YJ, Jung IK, Kwak EJ (2010) Quality characteristics and antioxidant activities of cookies added with Pleurotus eryngii powder. Korean J Food Sci Technol, 42, 183-189

21. Lee JH, Ko JC (2009) Physicochemical properties of cookies incorporated with strawberry powder. Food Eng Prog, 13, 79-84

22. Lim EJ, Huh CO, Kwon SH, Yi BS, Cho KR, Shin SG, Kim SY, Kim JY (2009) Physical and sensory characteristics of cookies with added leek (Allium tuberosum Rottler) powder. Korean J Food Nutr, 22, 1-7

23. Shin JH, Lee SJ, Choi DJ, Kwen OC (2007) Quality characteristics of cookies with added concentrations of garlic juice. Korean J Food Cookery Sci, 23, 609-614 